\title{
Tenis Antrenörleri Yeterlilik Düzeyinin Araştırılması
}

\author{
DOI: $10.26466 /$ opus.605062
}

$\underline{\text { Egemen Ermiș* }}^{*}$ - Arif Satıc1** - Özgür Bostanc1 ${ }^{* * *}$ - Osman İmamoğlu Mehmet Yalçın Taşmektepligil ${ }^{* * * *}$

* Arş. Gör., Ondokuz Mayıs Üniversitesi, Yaşar Doğu Spor Bilimleri Fakültesi, Samsun / Türkiye E-Posta: egemen.ermis@omu.edu.tr ORCID: 0000-0002-3976-6981

** Prof. Dr. Ondokuz Mayıs Üniversitesi, Yaşar Doğu Spor Bilimleri Fakültesi, Samsun / Türkiye E-Posta: arif.satici@omu.edu.tr ORCID: 0000-0003-4483-5619

*** Doç. Dr. Ondokuz Mayıs Üniversitesi, Yaşar Doğu Spor Bilimleri Fakültesi, Samsun / Türkiye E-Posta: bostanci@omu.edu.tr ORCID: 0000-0002-7952-1014 **** Prof. Dr., Ondokuz Mayıs Üniversitesi, Yaşar Doğu Spor Bilimleri Fakültesi, Samsun / Türkiye E-Postaｏsmani@omu.edu.tr ORCID: 0000-0001-6671-6042 ***** Prof. Dr., Ondokuz Mayıs Üni., Yaşar Doğu Spor Bilimleri Fakültesi, Samsun / Türkiye Öz

E-Posta myalcint@omu.edu.tr ORCID: $\quad$ 0000-0001-6542-7695
\end{abstract}

Bu çalışmada tenis antrenörlerinin farklı değişkenlere göre yeterliliklerinin karşılaştırılması amaçlanmıştır. Farklı kademelerdeki toplam 184 tenis antrenörüne kişisel bilgi formu yanında Antrenör Yeterlilik Ölçeği-II uygulanmıştır. İstatistiksel işlemlerde tek yönlü varyans analizi, LSD ve t-testleri kullanılmıştır. Yaş seviyesi, antrenör kademeleri, antrenörlük yapılan yer, milli olma, ve antrenörlük yılı kategorisine göre motivasyon, oyun stratejileri, teknik öğretimi, karakter oluşumu ve fiziksel kondisyon alt ölçeklerinde istatiksel olarak anlaml farklllık tespit edilmiştir $(p<0,05$ ve $p<0,001)$. Yaş seviyesi, antrenörlük kademesi ve antrenörlük yıl arttıkça alt ölçek puanları yükselmiştir. Stajyer antrenörlerin alt ölçek puanlar düşük bulunmuştur. Milli olan tenis antrenörlerinin alt ölçek puanlarının genelde diğgerlerinden daha yüksek olduğu görülmüştür. Yaş gruplarına göre 25 yaş ve altındakilerin ortalama puan 26 ve 31 yaş arasındakilerin puanlarından daha düşüktür. Antrenörlük kademesine göre, belge sahibi olmayan stajyer antrenörlerin ortalama puan 1. kademede ve 2. Kademe belge sahibi olanların puanlarından daha düşüktür. Sonuç: Tenis antrenörlerinin kortta harcadıkları mesaileri ve tecrübeleri arttıkça yeterliliklerinin yükseldiği sonucuna varılmıştır. Tenis antrenörlerinin yeterlilik düzeylerinin orta seviyede olduğu söylenebilir. Özellikle oyun stratejileri ve kondisyon yeterliliği konusunda daha fazla gelişim sağlamaları önerilir.

Anahtar Kelimeler: Tenis antrenörü, Yeterlilik, Öz yeterlilik 


\title{
Investigation of Self-efficacy Levels of Tennis Coaches
}

*

\begin{abstract}
The aim was to compare the self-efficacy of tennis coaches according to different variables. Personal information form and Coaching Self-efficacy Scale-II were given to a total of 184 tennis coaches of different levels. One way ANOVA, LSD and t-tests were used for statistical analysis. Statistically significant difference was found in motivation, game strategies, technical teaching, character formation and physical fitness in terms of age, coaching levels, place of coaching, state of being in the national team, and years of coaching $(p<0,05$ and $p<0,001)$. As age level, coaching level and years of coaching increased, subscale scores also increased. Subscale scores of trainee coaches were found to be low. Subscale scores of the national team tennis coaches were generally higher than the scores of others. In terms of age groups, the average scores of coaches aged 25 and younger were lower than those of coaches aged between 26 and 31. In terms of coaching ranks, the average scores of trainee coaches who did not have certificate were lower than those of coaches who had first and second rank certificates. It was concluded that the more time tennis coaches spent on the court and the more experience they had, the higher their self-efficacy was. It can be said that tennis coaches have moderate level of self-efficacy. It is recommended that they should improve more about game strategies and fitness efficacy.
\end{abstract}

Keywords: Tennis coach, Competence, Self-efficacy 


\section{Giriş}

Günümüzde sporun önemi herkes tarafından bilinmektedir, spor toplumun tüm yönlerini ve insanların yaşamlarını etkiler ve yaşamın ayrılmaz bir parçası haline gelmiştir. Sporda performansın arttırılması ve başarı elde edilmesinde sporcuların performanslarını arttırarak başarıyı yakalamaya çalışan antrenörler spor organizasyonlarında yer alan önemli aktörlerdir (Unutmaz ve Gencer, 2017). Sporcularının davranışlarını şekillendiren ve istenilen performansa ulaşmalarını sağlamak üzere çalışan antrenörlerin saha içi ya da saha dışı davranışları, başarının elde edilmesinde önem taşımaktadır. Bu nedenle, sporda liderlik araştırmaları içerisinde sıklıkla tanımlanmaya çalışılan konu, sporcuların performanslarını etkileyen antrenör davranışlarının belirlenmesidir (Horn, 2008). Horn (2002) tarafından ortaya konan Antrenör Etkililiği Modeli, antrenör davranışının, antrenörün beklentileri, inançları ve hedeflerine bağlı olarak, antrenörün bulunduğu örgütsel iklim ve antrenörün kişisel özellikleri ile sporcuların kişisel özelliklerinden dolaylı olarak etkilendiğini; antrenör davranışının ise sporcu performansını etkilediğini belirtmektedir.

Antrenörler sporcuların öğrenmesi ve performansıyla ilgilenirler ve etkili olabilmek için de birden fazla görev gerçekleştirmelidirler. Antrenörler etkili eğitim ve öğretim için hazırlık ve deneyimlerinin yeterli olmasına güvenmelidirler. Bununla birlikte sporcuların sportif yetenekleri ile okul ve toplum desteğine de güvenmelidirler. Bu nedenden dolayı antrenör yeterliğinin, etkili antrenörlükte güçlü bir değişken olduğu da düşünülmelidir (Koçak ve Güven, 2018).

Antrenör beklentileri ve inançları dikkate alındığında, bunların başarılı performans ile yakın ilişkili olduğu görülür ve aynı zamanda psikolojik etmenler de söz konusu olmaktadır (Feltz ve ark., 2008). Bu psikolojik etmenlerden biri öz yeterliliktir. Öz-yeterlilik kuramı, "bireylerin, verilen görevleri yerine getirip getiremeyeceklerine dair inançları" olarak tanımlanır ( Bandura, 1977).

Antrenörlük yeterliliği, antrenörlerin sporcularının öğrenmelerini ve performanslarını etkileyebilecek kapasiteye hangi ölçüde sahip olduklarına inanmaları olarak tanımlanmıştır (Feltz ve ark., 1999). Feltz ve ark. (1999) tarafından geliştirilen antrenörlük yeterliliği modeli, üç bileşen olarak geliştirilmiştir. Bu bileşenler; antrenör yeterliliği bilgi kaynakları, 
antrenör yeterliliği boyutları ve antrenör yeterliliğinin sonuçlarıdır. Daha sonra aynı yazarlar bu ve benzeri bilgileri antrenör yeterliliği modelini ölçmek üzere 4 alt boyutta toplamış (motivasyon, oyun/müsabaka stratejisi, teknik öğretimi, karakter oluşturma) ve toplam 24 maddeden oluşan Antrenör Yeterliliği Ölçeğini geliştirmişlerdir (Unutmaz ve Gencer, 2017). Daha sonra ölçek Myers ve ark. (2008) tarafından modifiye edilmiştir ve 5 alt boyutta toplam 18 maddeden oluşmuştur.

Antrenör yeterliliği bilgi kaynakları; antrenörlük tecrübesi/hazırlığı, daha önceki başarılar veya kazanma kaybetme oranı, algılanan sporcu becerileri ile takım dışından alınan (okul, aile, yöneticiler, toplum vb.) sosyal destektir. Antrenör yeterliliği; motivasyon, oyun/müsabaka stratejisi, teknik ve karakter oluşturma boyutlarından oluşmaktadır. (Unutmaz ve Gencer, 2017). Oyun/müsabaka stratejisi yeterliliği; antrenörlerin müsabaka sırasında liderlik edebilme özellikleridir. Teknik yeterlilik; antrenörlerin antrenman sırasındaki öğretimsel kapasitelerdir. Karakter oluşturma yeterliliği ise; spor yolu ile sporcularının karakter gelişimine olumlu etkilerine yönelik kapasitelerdir. Antrenör yeterliliğinin sonuçlarl; antrenör davranışı, oyuncu/takım memnuniyeti, oyuncu/takım performansı ve oyuncu/takım yeterliliği olarak görülür (Feltz ve ark.,1999). İnsan bir işi gerçekleştirebilmek için yeterli beceri düzeyine sahip olup olmadığına yönelik inancı sonucunda davranış ortaya koyar (Sshunk, 2009). Kişilerin yeterlik inançlarının sorguları, -ebilme sorusunun çevresinde döner (bu problemi çözebilir miyim?, araba sürebilir miyim?, iyi yazı yazabilir miyim? vb.) Bu sebeple, öz yeterlik inançları çoğunlukla "kendine güvene" yönelik göndermede bulunur (Pajares ve Schunk, 2002).

Bu doğrultuda, öz yeterlik inancı bireylerin olumlu ya da olumsuz düşünmesini, hedef ve amaçlar belirlemesini, hedef ve amaçlara ulaşabilmek için yöntem geliştirmesini içerir. Ayrıca zorluklara karşı ne kadar çaba harcayacağını, çabalarının sonucunu, işsel güdüsünü, diğer bireylere ve topluma karşı hissettiği duyguların niteliğini, yaşamındaki seçimlerini ve genel anlamda stres seviyesini etkilemesi bakımından hayattaki öneminin büyük olduğu söylenebilir (Koçak ve Güven, 2018; Bandura, 2001).

Bu çalışmada Tenis Antrenörlerinin farklı değişkenler yönünden yeterliliklerinin araştırılması amaçlanmıştır. 


\section{Yöntem}

Çalışmaya dahil edilen farklı kademelerdeki toplam 184 tenis antrenörüne Antrenör Yeterlilik Ölçeği-II uygulanmıştır. Myers, Feltz, Chase, Reckase ve Hancock (2008) tarafından modifiye edilen Antrenör Yeterlilik Ölçeği-II 5 alt boyut (motivasyon, oyun stratejileri, teknik öğretimi, karakter oluşumu, fiziksel kondisyon) altında toplanmış ve 18 maddeden oluşmaktadır. Motivasyon 4 madde, oyun stratejileri 4 madde, teknik öğretimi 4 madde, karakter 3 madde ve fiziksel kondisyon 3 maddeyi kapsamaktadır. Ölçekte yer alan maddeler 4'lü Likert (1-Az, 2-Orta, 3Yüksek ve 4-Tam) derecelendirme sistemi ile ölçülmektedir. Ölçekten alınabilecek en düşük puan 18 antrenörlerin yeterliliğinin kötü ve alınabilecek en yüksek puan ise 72 antrenörlerin yeterlilik yönünden çok iyi olduğunu ifade eder. Yeterlilik Puanının düşük olması antrenörlerin antrenör yeterliliği açısından az yeterli olduğu, puanın yüksek olması yeterlik açısından antrenörlerin iyi olduğu anlamını taşır (Unutmaz ve Gencer,2017). Çalışmada verilerin analizi için SPSS 23 paket programı kullanılmıştır. Veriler değerlendirilirken "Kolmogorov Smirnov Testi" ile normal dağılıma uygunluğu araştırılmış ve tüm verilerin normal dağılıma uyduğu tespit edilmiştir. İkili karşılaştırmalarda t- testi ve çoklu karşılaştırmalarda tek yönlü varyans analizi (ANOVA) ve farklılığın tespiti için LSD testleri uygulanmıştır.

\section{Bulgular}

Yaş seviyesine göre antrenör yeterlilikleri alt boyutlarında motivasyon yeterliliği, oyun, teknik öğretim yeterliliği, kişilik kazandırma ve kondisyon yeterliliğinde önemli farklılıklar tespit edilmiştir $(p<0,05$ ve $\mathrm{p}<0,001)$. Bu farklılık genel olarak 25 yaş ve altı gruptan kaynaklanmıştır 
Egemen Ermiş - Arif Satıcı - Özgür Bostancı - Osman İmamoğlu - Mehmet Yalçın Taşmektepligil

Tablo 1. Yaş Seviyesine Göre Antrenör Yeterliliklerin Karşılaştırılması

\begin{tabular}{|c|c|c|c|c|c|}
\hline & & $\mathrm{N}$ & Ortalama & St.sapma & F/LSD \\
\hline \multirow{4}{*}{$\begin{array}{l}\text { Motivasyon } \\
\text { Motivasyon } \\
\text { Yeterliliği }\end{array}$} & / 25 yaş ve altı & 94 & 9,96 & 2,70 & \multirow{4}{*}{$\begin{array}{l}25,92^{* *} \\
1<2,3 \\
2<3\end{array}$} \\
\hline & $26-31$ & 30 & 11,93 & 2,69 & \\
\hline & 32 ve üzeri & 60 & 12,90 & 2,17 & \\
\hline & Toplam & 184 & 11,24 & 2,86 & \\
\hline \multirow[t]{4}{*}{ Oyun } & 25 yaş ve altı & 94 & 7,32 & 3,31 & \multirow{4}{*}{$\begin{array}{l}64,42^{* *} \\
1<2,3\end{array}$} \\
\hline & $26-31$ & 30 & 11,53 & 2,60 & \\
\hline & 32 ve üzeri & 60 & 12,50 & 2,38 & \\
\hline & Toplam & 184 & 9,70 & 3,81 & \\
\hline \multirow{4}{*}{$\begin{array}{l}\text { Teknik/Teknik } \\
\text { öğretim } \\
\text { yeterliliği }\end{array}$} & 25 yaş ve altı & 94 & 8,77 & 3,15 & \multirow{4}{*}{$\begin{array}{l}52,04^{* *} \\
1<2,3 \\
2<3\end{array}$} \\
\hline & $26-31$ & 30 & 11,53 & 2,03 & \\
\hline & 32 ve üzeri & 60 & 13,30 & 2,30 & \\
\hline & Toplam & 184 & 10,70 & 3,41 & \\
\hline \multirow{4}{*}{$\begin{array}{l}\text { Karakter/ } \\
\text { Kişilik } \\
\text { kazandırma }\end{array}$} & 25 yaş ve altı & 94 & 7,74 & 2,62 & \multirow{4}{*}{$\begin{array}{l}25,12^{* *} \\
1<2,3 \\
2<3\end{array}$} \\
\hline & $26-31$ & 30 & 9,27 & 2,15 & \\
\hline & 32 ve üzeri & 60 & 10,37 & 1,64 & \\
\hline & Toplam & 184 & 8,85 & 2,55 & \\
\hline \multirow{4}{*}{$\begin{array}{l}\text { Kondisyon/ } \\
\text { Kondisyon } \\
\text { yeterliliği }\end{array}$} & 25 yaş ve altı & 94 & 5,81 & 2,34 & \multirow{4}{*}{$\begin{array}{l}33,34^{* *} \\
1<2,3\end{array}$} \\
\hline & $26-31$ & 30 & 8,27 & 2,15 & \\
\hline & 32 ve üzeri & 60 & 8,50 & 1,89 & \\
\hline & Toplam & 184 & 7,09 & 2,53 & \\
\hline
\end{tabular}

${ }^{*} p<0,05 v e^{* *} p<0,001$

Tablo 2. Antrenör Kademelerine Göre Antrenör Yeterliliklerin Karşılaştırılması

\begin{tabular}{|c|c|c|c|c|c|}
\hline & & $\mathbf{N}$ & Ort. & St.sapma & F/LSD \\
\hline \multirow[t]{5}{*}{ Motivasyon } & Kademe (1) & 46 & 11,13 & 2,79 & \multirow{5}{*}{$\begin{array}{l}22,83^{* *} \\
1,2<3 \\
1,2>4 \\
4<3\end{array}$} \\
\hline & Kademe (2) & 58 & 12,00 & 2,55 & \\
\hline & Kademe (3) & 28 & 13,64 & 2,02 & \\
\hline & Stajyer (4) & 52 & 9,19 & 2,24 & \\
\hline & Toplam & 184 & 11,24 & 2,86 & \\
\hline \multirow[t]{5}{*}{ Oyun } & Kademe (1) & 46 & 9,35 & 3,56 & \multirow{5}{*}{$\begin{array}{l}52,07^{* *} \\
1<2,3 \\
1,2,3>4\end{array}$} \\
\hline & Kademe (2) & 58 & 11,93 & 2,51 & \\
\hline & Kademe (3) & 28 & 12,71 & 2,81 & \\
\hline & Stajyer (4) & 52 & 5,88 & 2,01 & \\
\hline & Toplam & 184 & 9,70 & 3,81 & \\
\hline \multirow[t]{5}{*}{ Teknik } & Kademe (1) & 46 & 10,17 & 3,37 & \multirow{5}{*}{$\begin{array}{l}46,08^{* *} \\
1<2,3 \\
2<3 \\
4<1,2,3\end{array}$} \\
\hline & Kademe (2) & 58 & 12,07 & 2,23 & \\
\hline & Kademe (3) & 28 & 14,21 & 1,77 & \\
\hline & Stajyer (4) & 52 & 7,73 & 2,53 & \\
\hline & Toplam & 184 & 10,70 & 3,41 & \\
\hline \multirow[t]{5}{*}{ Karakter } & Kademe (1) & 46 & 8,91 & 2,19 & \multirow{5}{*}{$\begin{array}{l}24,48^{* *} \\
1,2,3>4\end{array}$} \\
\hline & Kademe (2) & 58 & 9,90 & 2,11 & \\
\hline & Kademe (3) & 28 & 10,36 & 1,79 & \\
\hline & Stajyer (4) & 52 & 6,81 & 2,38 & \\
\hline & Toplam & 184 & 8,85 & 2,55 & \\
\hline
\end{tabular}




\begin{tabular}{|c|c|c|c|c|c|}
\hline \multirow[t]{5}{*}{ Kondisyon } & Kademe (1) & 46 & 6,87 & 2,35 & \multirow{5}{*}{$\begin{array}{l}27,26^{* *} \\
1<2,3 \\
4<1,2,3\end{array}$} \\
\hline & Kademe (2) & 58 & 8,34 & 1,84 & \\
\hline & Kademe (3) & 28 & 8,57 & 2,39 & \\
\hline & Stajyer (4) & 52 & 5,08 & 2,02 & \\
\hline & Toplam & 184 & 7,09 & 2,53 & \\
\hline \multirow{5}{*}{$\begin{array}{l}\text { Toplam } \\
\text { Yeterlilik }\end{array}$} & Kademe (1) & 46 & 46,43 & 13,07 & \multirow{5}{*}{$\begin{array}{l}46,95^{* *} \\
1<2,3 \\
2<3 \\
4<1,2,3\end{array}$} \\
\hline & Kademe (2) & 58 & 54,24 & 10,15 & \\
\hline & Kademe (3) & 28 & 59,50 & 9,69 & \\
\hline & Stajyer (4) & 52 & 34,69 & 8,16 & \\
\hline & Toplam & 184 & 47,57 & 13,78 & \\
\hline
\end{tabular}

${ }^{* *} p<0,001$

Antrenörlük kademesine göre, belge sahibi olmayan stajyer antrenörlerin ortalama puanı 34,69 iken 1. kademedekilerin 46,43 puan 2. kademedekilerin 54,24 puan ve 3 . Kademe antrenörlerin ise 59,50 puandir. Çalışmaya katılan tüm antrenörlerin ortalama puanı ise 47,57'dir. Antrenör Kademelerine Göre Antrenör Yeterliliklerin Karşılaştırılmasında 2. Ve 3. Kademe antrenörlerin yeterliliklerinin daha iyi olduğu görülmüştür $(\mathrm{p}<0,05$ ve $\mathrm{p}<0,001)$.

Tablo 3. Antrenörlük Yapılan Yere göre yeterliliklerin Karşılaştırılması

\begin{tabular}{|c|c|c|c|c|c|}
\hline & & $\mathbf{N}$ & Ortalama & St. sapma & F/LSD \\
\hline \multirow[t]{4}{*}{ Motivasyon } & Kulüp & 96 & 12,42 & 2,58 & \multirow{4}{*}{$\begin{array}{l}16,84^{* *} \\
1,2>3\end{array}$} \\
\hline & Okul & 22 & 12,09 & 2,21 & \\
\hline & Stajyer Antrenör & 66 & 9,24 & 2,40 & \\
\hline & Toplam & 184 & 11,24 & 2,87 & \\
\hline \multirow[t]{4}{*}{ Oyun } & Kulüp & 96 & 11,92 & 2,65 & \multirow{4}{*}{$\begin{array}{l}72,56^{* *} \\
1,2>3\end{array}$} \\
\hline & Okul & 22 & 12,00 & 2,37 & \\
\hline & Stajyer Antrenör & 66 & 5,70 & 1,93 & \\
\hline & Toplam & 184 & 9,70 & 3,82 & \\
\hline \multirow[t]{4}{*}{ Teknik } & Kulüp & 96 & 12,40 & 2,46 & \multirow{4}{*}{$\begin{array}{l}44,51^{* *} \\
1,2>3\end{array}$} \\
\hline & Okul & 22 & 12,91 & 2,34 & \\
\hline & Stajyer Antrenör & 66 & 7,48 & 2,45 & \\
\hline & Toplam & 184 & 10,70 & 3,42 & \\
\hline \multirow[t]{4}{*}{ Karakter } & Kulüp & 96 & 10,00 & 1,92 & \multirow{4}{*}{$\begin{array}{l}22,62^{* *} \\
1,2>3\end{array}$} \\
\hline & Okul & 22 & 9,73 & 2,10 & \\
\hline & Stajyer Antrenör & 66 & 6,88 & 2,34 & \\
\hline & Toplam & 184 & 8,85 & 2,55 & \\
\hline \multirow[t]{4}{*}{ Kondisyon } & Kulüp & 96 & 8,35 & 2,01 & \multirow{4}{*}{$\begin{array}{l}36,78^{* *} \\
1,2>3\end{array}$} \\
\hline & Okul & 22 & 8,36 & 1,57 & \\
\hline & Stajyer Antrenör & 66 & 4,82 & 1,83 & \\
\hline & Toplam & 184 & 7,09 & 2,54 & \\
\hline
\end{tabular}

${ }^{*} p<0,05 v e{ }^{* *} p<0,00$ 
Antrenörlük yapılan yere göre yeterliliklerin karşılaştırılmasında kulüp ve okul antrenörlerinin stajyer antrenörlere göre ölçek alt boyutlarından aldığı puanlar daha iyi olması istatistiksel olarak farklılık göstermektedir $(\mathrm{p}<0,001)$.

Tablo 4. Milli olma durumuna göre yeterliliklerin Karşılaştırılması

\begin{tabular}{|c|c|c|c|c|c|}
\hline & Kategori & $\mathrm{N}$ & Ortalama & St.sapma & T-test \\
\hline \multirow[t]{2}{*}{ Motivasyon } & Milli & 24 & 14,22 & 1,48 & \multirow[t]{2}{*}{$3,47^{* *}$} \\
\hline & Milli değil & 160 & 10,92 & 2,80 & \\
\hline \multirow[t]{2}{*}{ Oyun } & Milli & 24 & 14,11 & 1,69 & \multirow[t]{2}{*}{$3,93^{* *}$} \\
\hline & Milli değil & 160 & 9,22 & 3,68 & \\
\hline \multirow[t]{2}{*}{ Teknik } & Milli & 24 & 15,11 & 0,93 & \multirow[t]{2}{*}{$4,48^{* *}$} \\
\hline & Milli değil & 160 & 10,22 & 3,25 & \\
\hline \multirow[t]{2}{*}{ Karakter } & Milli & 24 & 10,89 & 1,54 & \multirow[t]{2}{*}{$2,60^{*}$} \\
\hline & Milli değil & 160 & 8,63 & 2,55 & \\
\hline \multirow[t]{2}{*}{ Kondisyon } & Milli & 24 & 9,33 & 1,50 & \multirow[t]{2}{*}{$2,91^{*}$} \\
\hline & Milli değil & 160 & 6,84 & 2,51 & \\
\hline
\end{tabular}

${ }^{*} p<0,05 v e^{* *} p<0,001$

Millilik seviyesine göre alt ölçek puanları milli olmayanlarda en düşük kondisyon 6,84 ve en yüksek motivasyon 10,92 puan iken milli olanlarda en düşük kondisyon puanı 9,33 ve en yüksek teknik öğretimi 15,11 puan olarak bulunmuştur. Millilik seviyesine göre alt ölçek puanları arasında istatistiksel olarak anlamlı farklılık tespit edilmiştir ( $\mathrm{p}<0,05$ ve $\mathrm{p}<0,001)$.

Tablo 5. Antrenörlük yılına göre Antrenör yeterliliklerin Karşılaştırılması

\begin{tabular}{|c|c|c|c|c|c|}
\hline & Antrenörlük yılı & $\mathbf{N}$ & Ortalama & St. sapma & F/LSD \\
\hline \multirow[t]{4}{*}{ Motivasyon } & 2 yildan az (1) & 110 & 10,24 & 2,86 & \multirow{4}{*}{$\begin{array}{l}10,02^{* *} \\
1<2,3\end{array}$} \\
\hline & 3-8 yil (2) & 30 & 12,87 & 2,13 & \\
\hline & 8 yıldan fazla (3) & 44 & 12,64 & 2,26 & \\
\hline & Toplam & 184 & 11,24 & 2,87 & \\
\hline \multirow[t]{4}{*}{ Oyun } & 2 yıldan az (1) & 110 & 7,87 & 3,55 & \multirow{4}{*}{$\begin{array}{l}23,20^{* *} \\
1<2,3\end{array}$} \\
\hline & 3-8 yil (2) & 30 & 12,27 & 2,19 & \\
\hline & 8 yıldan fazla (3) & 44 & 12,50 & 2,43 & \\
\hline & Toplam & 184 & 9,70 & 3,82 & \\
\hline \multirow[t]{4}{*}{ Teknik } & 2 yıldan az (1) & 110 & 8,95 & 2,99 & \multirow{4}{*}{$\begin{array}{l}29,08^{* *} \\
1<2,3\end{array}$} \\
\hline & $3-8$ yil (2) & 30 & 13,00 & 1,89 & \\
\hline & 8 yıldan fazla (3) & 44 & 13,50 & 2,30 & \\
\hline & Toplam & 184 & 10,70 & 3,42 & \\
\hline \multirow[t]{2}{*}{ Karakter } & 2 yıldan az (1) & 110 & 7,98 & 2,72 & $9,33^{* *}$ \\
\hline & 3-8 y1l (2) & 30 & 10,27 & 1,44 & $1<2,3$ \\
\hline
\end{tabular}




\begin{tabular}{lllll}
\hline & 8 yıldan fazla (3) & 44 & 10,05 & 1,70 \\
\cline { 2 - 5 } & Toplam & 184 & 8,85 & 2,55 \\
\hline \multirow{2}{*}{ Kondisyon } & 2 y1ldan az (1) & 110 & 6,22 & 2,56 \\
\cline { 2 - 5 } & 3-8 y1l (2) & 30 & 8,40 & 1,96 \\
\cline { 2 - 5 } & 8 y1ldan fazla (3) & 44 & 8,36 & 1,89 \\
\cline { 2 - 4 } & Toplam & 184 & 7,09 & 2,54 \\
\hline
\end{tabular}

${ }^{*} p<0,05 v e^{* *} p<0,001$

Antrenörlük yılına göre antrenör yeterliliklerin karşılaştırılmasında ölçek alt boyutlarında 2 yıldan az antrenörlük yapanların puanları 3-8 yıl ve 8 yıldan daha fazla antrenörlük yapanlardan daha düşük bulunması istatistiksel olarak önemlidir $(\mathrm{p}<0,001)$.

Tablo 6. Ölçekten alınan puanların en yüksek puanlara göre yüzde durumlarının gösterimi

\begin{tabular}{llll}
\hline Ölçek ve boyutları & $\begin{array}{l}\text { Alınan } \\
\text { ortalama puan }\end{array}$ & $\begin{array}{l}\text { Alınabilecek en } \\
\text { yüksek puan }\end{array}$ & $\begin{array}{l}\text { En Yüksek puana göre } \\
\text { alınan puan \%durumu }\end{array}$ \\
\hline Motivasyon Yeterliliği & 11,24 & 16 & 70,25 \\
\hline Oyun/Müsabaka stratejileri & 9,70 & 16 & 60,63 \\
\hline Teknik öğretim yeterliliği & 10,70 & 16 & 66,88 \\
\hline Kişilik kazandırma & 8,85 & 12 & 73,75 \\
\hline Kondisyon yeterliliği & 7,09 & 12 & 59,08 \\
\hline Toplam ölçek puan & 47,57 & 72 & 66,07 \\
\hline
\end{tabular}

Tablo 6'ya göre ölçekten alınması gereken puana göre alınan en yüksek puan \% olarak kişilik kazandırma boyutunda alınmıştır $(\% 73,75)$. Buna karşılık en düşük puan ise \%59,08 ile kondisyon yeterliliği boyutundadır. Toplam ölçekten alınan puan yüzdesi ise alınabilecek puanın $\% 66,07$ 'si olarak bulunmuştur. Tenis antrenörlerinin yeterlilik düzeylerinin orta seviyede olduğu söylenebilir.

\section{Tartışma}

$\mathrm{Bu}$ çalışmada tenis antrenörlerinin farklı değişkenlere göre yeterlilikleri karşılaştırılmıştır. Çalışmamızda ilk olarak antrenörlerin yeterlik düzeyleri yaş seviyelerine göre karşılaştırılmıştır. Antrenörlerin yaş seviyelerine göre karşılaştırılmasında motivasyon, oyun stratejileri, teknik öğretimi, karakter oluşumu ve fiziksel kondisyon alt ölçeklerinde istatiksel olarak anlamlı farklılık tespit edilmiştir. Tüm alt ölçeklerde antrenörlerin 
yaşı arttıkça yeterliliklerinin arttığ1 tespit edilmiştir. Benzer şekilde, Köksal (2008) çalışmasında yaş ilerledikçe öz-yeterliliğin arttığını tespit etmiş ve antrenörlerin yaşları ile öz yeterlilikleri arasındaki farkın istatistiksel olarak anlamlı olduğunu belirmiştir. Güllü ve Donuk (2019)'un sonuçlarına göre de grup ortalamaları arasındaki farklar; tüm alt boyutlarda anlamlı bulunmuştur. Köksal (2008)'ın sonuçlarına göre 21-30 yaş ile 3140 yaş arasındaki antrenörlerin öz yeterlilikleri 51 yaş ve üzerindeki antrenörlere göre ve 21-30 yaş arasındaki antrenörlerin öz yeterlilikleri 4150 yaşarasındaki antrenörlere göre daha düşüktür. Antrenörlerin yaşlarının arttıkça öz-yeterliliklerinde artış görülmesinin sebebinin yaşla birlikte artan mesleki deneyim ve hayat tecrübesi olduğu söylenebilir. Yüksek öz yeterlik inancının bireysel performans üzerinde olumlu etkisi olduğunu gösteren araştırma bulgularından hareketle, yüksek öz yeterlik inancına sahip olan üyelerden oluşan grupların performans düzeylerinin daha yüksek olacağını düşünmek mümkündür (Öcel, 2002). Antrenörlerin yaş seviyelerine göre karşılaştırılmasında anlamlı farklılık tespit eden çalışma bulgularımızın aksine, katılımcıların öz yeterlilik düzeylerinin yaş değişkenine göre istatistiksel olarak anlamlı olmadığ sonucuna ulaşan çalışmalar da vardır. Koçak (2019), antrenör adaylarının özyeterlilik düzeyini incelediği araştırmada katılımcıların öz yeterlilik düzeylerinin yaş değişkenine göre istatistiksel olarak anlamlı olmadığını bildirmiş̧ir. Kowalski (2007) de aday futbol altyapı antrenörlerinde yaş değişkeninin antrenör öz yeterliğine herhangi bir etkisinin olmadığını belirtmiştir. Bu çalışmalarda antrenör adaylarının öz-yeterlilik düzeyinde yaşa göre anlamlı farklılık bulunmamasının sebebi katılımcıların antrenör adayı olması ve henüz antrenörlük mesleğinde yeterli tecrübelerinin olmaması olabilir.

Çalışmamızda ikinci olarak antrenörlük kademelerine göre antrenör yeterlilikleri karşılaştııılmıştır. Çalışmamıza katılan toplam 184 antrenörden 46's1 1. kademe antrenörlük belgesine sahipken, 58'i 2. kademe ve 28 'i 3 . kademe antrenörlük belgesine sahiptir. Katılımclların 52 'si ise stajyer antrenördür. Toklu (2010)'un çalışmasında ise araştırmaya katılan 177 antrenörden 1. Kademe antrenörlük belgesine sahip olan 94 kişi, 2. kademe antrenörlük belgesine sahip olan 54 kişi, 3. kademe antrenörlük belgesine sahip olan 25 kişi, 4 . kademe antrenörlük belgesine sahip olan 3 kişi ve 5 . kademe antrenörlük belgesine sahip olan 1 kişidir. Antrenör- 
lerin kademelerine göre karşılaştırılmasında motivasyon, oyun stratejileri, teknik öğretimi, karakter oluşumu ve fiziksel kondisyon alt ölçeklerinde istatiksel olarak anlamlı farklılık tespit edilmiştir. Çalışmamızda antrenörlerin kademeleri arttıkça öz-yeterlilik düzeylerinin arttığı bulunmuştur. Tüm alt boyutlarda en düşük öz-yeterlilik seviyesine sahip antrenörler stajyer antrenörler iken, 1. kademe antrenörlerin öz-yeterlilik seviyesi 2. kademe antrenörlerinkinden daha düşük, 2. kademe antrenörlerin öz-yeterlilik seviyesi ise 3. kademe antrenörlerinkinden daha düşük olarak bulunmuştur. Benzer şekilde, Köksal (2008), çalışmasında birinci kademe ve üçüncü kademe antrenörlerin öz yeterlikleri arasındaki fark istatistiksel olarak anlamlı bulunmuştur. 1. kademe antrenörlük belgesine sahip antrenörlerin öz yeterlikleri 3. kademe antrenörlük belgesine sahip antrenörlere göre daha düşüktür. Bu sonuçların antrenörlük kademesi arttıkça antrenörlerin daha fazla mesleki bilgi ve beceriye sahip olmalarından kaynaklandığı söylenebilir.

Çalışmamızda üçüncü olarak antrenörlerin antrenörlük yaptıkları yere göre öz-yeterlilikleri karşılaştırılmıştır. Antrenörlerin antrenörlük yaptıkları yere göre karşılaştırılmasında motivasyon, oyun stratejileri, teknik öğretimi, karakter oluşumu ve fiziksel kondisyon alt ölçeklerinde istatiksel olarak anlamlı farklılık tespit edilmiştir. Toklu (2010), çalışmasında antrenörlerin öz yeterliliklerinin görev yaptıkları yere göre karşılaştırılmasında kulüplerde çalışan antrenörlerle otelde çalışan antrenörler arasında istatistiksel olarak anlamlı bir farklılık tespit edilmediğini bulmuştur.

Çalışmamızda dördüncü olarak antrenörlerin milli olma durumuna göre öz-yeterlilikleri karşılaştırılmıştır. Çalışmamıza katılan toplam 184 antrenörden 24'ü milli, 160'ı ise milli değildir. Antrenörlerin milli olma durumuna göre karşılaştırılmasında motivasyon, oyun stratejileri, teknik öğretimi, karakter oluşumu ve fiziksel kondisyon alt ölçeklerinde istatiksel olarak anlamlı farklılık tespit edilmiştir. Tüm alt ölçeklerde milli olan antrenörlerin öz-yeterliliklerinin daha fazla olduğu bulunmuştur. Koçak (2019)'ın çalışmasında da milli takımlarda sporcu olarak yer almış katılımcıların öz yeterlik düzeylerinin fiziksel kondisyon ve oyun stratejileri boyutunda milli sporculuk yapmamış olanlara oranla daha yüksek olduğu belirlenmiştir. Milli takımlar gibi elit seviyede sporcu olarak edinilen bilgi ve becerilerin antrenörlük öz yeterliklerini olumlu yönde etki- 
lemesi muhtemeldir. Bu sonuçlara göre milli sporculuk geçmişinin antrenörlerin öz yeterliklerine olumlu yönde etki ettiği söylenebilir.

Çalışmamızda son olarak antrenörlerin antrenörlük yılına göre özyeterlilikleri karşılaştııılmıştır. Çalışmamıza katılan toplam 184 antrenörden 110'u 3 yıldan az süredir antrenörlük yapmaktayken, 30'unun antrenörlük süresi 3 ila 8 yıl arasıdır ve $44^{\prime}$ ü ise 8 yıldan fazla süredir antrenörlük yapmaktadır. Antrenörlerin antrenörlük yılına göre karşılaştırılmasında motivasyon, oyun stratejileri, teknik öğretimi, karakter oluşumu ve fiziksel kondisyon alt ölçeklerinde istatiksel olarak anlamlı farklılık tespit edilmiştir. Tüm alt ölçeklerde antrenörlerin antrenörlük yılı arttıkça yeterliliklerinin arttığı tespit edilmiştir. Benzer şekilde, Köksal (2008), antrenörlerin antrenörlük yılına göre karşılaştırılmasında istatiksel olarak anlamlı farklılık tespit etmiştir. Çelik (2005)'in araştırma sonuçlarına göre ise antrenörlerin \%33'ü 0-3 yıldır, \%22'si 4-6 yıldır, \%16'sı 7-9 yıldır, \%12'si 10-12 yıldır, \%6'sı 13-15 yıldır, \%11'i 15 yıl ve üzerinde süredir antrenörlük yapmaktadır. İmamoğlu (2001) ise bireysel ve takım sporu antrenörleri üzerinde yaptığ 1 çalışmasında antrenörlerin büyük bir çoğunluğunun 6 ile 10 yı1 arasında antrenörlük yaptıklarını bildirmiştir.

Çalışmamızda ölçekten alınması gereken puana göre alınan en yüksek puan yüzde olarak kişilik kazandırma boyutundadır $(\% 73,75)$. Buna karşılık en düşük puan ise \%59,08 ile kondisyon yeterliliği boyutundadır. Çalışmamızın sonuçlarına göre tenis antrenörlerinin yeterlilik düzeylerinin orta seviyede olduğu söylenebilir. Cervone ve Peake (1986), tarafından yapılan bir araştırmada elde edilen bulgular, yüksek öz yeterlik inancına sahip olan deneklerin daha iyi performans sergilediklerini, başarısızlık sonrasında görevi daha uzun süre devam ettirdiklerini ve kendileri hakkında daha olumlu değerlendirmeler yaptıklarını göstermiştir. Çalışmamıza katılan antrenörlerin ölçekten aldıkları en yüksek puana göre antrenör yeterlilikleri tüm alt boyutlarda ortalamanın üzerinde bir değere sahiptir. Öz-yeterlilik inancı kişinin, yaşanmışlıkları ile beraber ve aynı zamanda kişinin kendi yaptıklarını başkalarının yaptıkları ile karşılaştırarak oluşur. Bu inancın yüksek olması kişinin kendine de güvenmesini sağlayacak, bu da kendini iyi ifade etmesi için önemli bir zemin hazırlayacaktır. 


\section{Sonuç ve Öneriler}

Tenis antrenörlerinin kortta harcadıkları mesaileri ve tecrübeleri arttıkça yeterliliklerinin yükseldiği sonucuna varılmıştır. Tenis antrenörlerinin yeterlilik düzeyleri orta seviyede olduğu söylenebilir. Özellikle oyun stratejileri ve kondisyon yeterliliği konusunda daha fazla gelişim sağlamaları araştırma kısıtları ve gelecek araştırmalar için önem arz etmektedir. 


\title{
EXTENDED ABSTRACT
}

\section{Investigation of Self-efficacy Levels of Tennis Coaches}

\author{
* \\ Egemen Ermiş - Arif Satıcı - Özgür Bostancı - Osman İmamoğlu - Mehmet \\ Yalçın Taşmektepligil \\ Samsun Ondokuz Mayıs University
}

Nowadays, the importance of sport is known by everyone, sport affects all aspects of society and people's lives and it has become an integral part of life. Coaches who try to achieve success by increasing the performance of the athletes in increasing the performance and achieving success in sports are important actors in the sports organizations. On-site or off-site behaviors of coaches who shape the behavior of their athletes and who work to ensure that they achieve the desired performance are important in achieving success.

Coaching efficacy is defined as the degree to which coaches believe that they have the capacity to influence the learning and performance of their athletes. Coaching efficacy consists of sub-dimensions of motivation, game / competition strategy, technique and character formation. Motivation competence represents the belief of coaches in their ability to influence athletes' psychological states and skills. Competence of game / competition strategy is the ability of the coaches to lead during the competition. Technical competence is instructional capacities of coaches during training. Character formation competence is capacities for the positive effects of athletes on character development through sports. Results of coaching efficacy are coach behavior, player / team satisfaction, player / team performance and player / team competence.

In this respect, self-efficacy beliefs include individuals' thinking positively or negatively, setting goals and objectives, and developing methods for achieving goals and objectives. In addition, it can be said that it has a great importance in life since it influences how much effort the individual will make against difficulties, the results of the efforts, professional motivation, the qualification of feelings for other individuals and 
the society, the choices the individual makes in life and the level of stress in general. Therefore, in this study, the aim was to compare the selfefficacy of tennis coaches according to different variables.

A total of 184 tennis coaches of different levels included in the study were given a personal information and Coaching Self-efficacy Scale-II. Coaching Self-efficacy Scale-II modified by Myers, Feltz, Chase, Reckase and Hancock (2008) consists of 18 items that are grouped under 5 subdimensions (motivation, game strategies, technical instruction, character formation, physical fitness). Motivation includes 4 items, game strategies includes 4 items, technical instruction includes 4 items, character includes 3 items and physical condition includes 3 items. The lowest score from the scale is 18 , while the highest score is 72 . In the study, SPSS 23 package program was used for data analysis. While evaluating the data, normality distribution was investigated with Kolmogorov Smirnov Test and all the data were found to comply with the normal distribution. Independent t-test was used for binary comparisons, one-way analysis of variance (ANOVA) was used for multiple comparisons, and LSD tests were used to find out the differences.

Statistically significant difference was found in the sub-scales of motivation, game strategies, technical teaching, character formation and physical fitness in terms of age, coaching levels, place of coaching, the state of being in the national team, and years of coaching ( $p<0,05$ and $\mathrm{p}<0,001)$. As the age level, coaching level and years of coaching increased, the subscale scores also increased. Subscale scores of trainee coaches were found to be low. The subscale scores of the national team tennis coaches were generally higher than the scores of others.

In terms of age groups, the average scores of coaches aged 25 and younger was 39.60, while the average scores of coaches aged between 2631 were 52.53 and the average scores of coaches aged 32 and older was 57.57. According to the coaching levels, the average score of trainee coaches who do not have a certificate was 34.69 , while it was 46.43 for the coaches with a certificate of first level, 54.24 for the coaches with a certificate of second level and 59.50 for the coaches with a certificate of third level. The average score of all coaches participating in the study was 47.56 . 
The highest score was taken from character formation sub-dimension in $\%(73,75 \%)$. On the other hand, the lowest score is in the fitness competence sub-dimension with $59.08 \%$. The percentage of scores obtained from the total scale was found to be $66.07 \%$ of the total score that one could get. It can be said that tennis coaches' self-efficacy levels are moderate.

Conclusion: It was concluded that the more time tennis coaches spent on the court and the more experience they had, the higher their self-efficacy was. It can be said that tennis coaches have moderate level of selfefficacy. It is recommended that they should improve more about game strategies and fitness efficacy.

\section{Kaynakça / References}

Bandura, A. (1977). Self-efficacy: Toward a unifying theory of behavioral change. Psychological review, 84(2), 191-215.

Bandura A (2001): Social cognitive theory: an angetic perspective. Annual Reviev of Psychology, 54(1), 1-26.

Cervone, D. ve Peake, P.K. (1986) Ancholoring, efficacy, and action: The influence of Judgmental heuristic on self efficacy judgments and behavior. Journal of Personality and Social Psychology, 50, 492-501.

Çelik, V.O. (2005) Amatör futbol antrenörlerinin liderlik özellikleri üzerine bir araştırma, Yayınlanmamış Yüksek Lisans Tezi, Anadolu Üniversitesi, Sağlık Bilimleri, Enstitüsü, Eskişehir.

Feltz, D. L., Chase, M. A., Moritz, S. E., ve Sullivan, P. J. (1999). A conceptual model of coaching efficacy: Preliminary investigation and instrument development. Journal of Educational Psychology, 91(4), 765-776.

Güllü, S. ve Donuk, B. (2019). Futbol antrenörlerinin duygusal emek ve antrenör yeterlilikleri arasındaki ilişkinin incelenmesi. Tarih Okulu Dergisi (TOD), 12(38), 58-79.

Horn, T. S. (2002). Coaching effectiveness in the sport domain. In (T. S. Horn Ed.), Advances in sport psychology (2nd ed.), (p.309-354). Champaign,IL: Human Kinetics.

Horn, T. S. (2008). Coaching effectiveness in the sport domain. In T. S. Horn (Ed.), Advances in sport psychology (3rd ed.), (p. 239-268). Champaign, IL: Human Knetics.

İmamoğlu, R. (2001). Bazı takım ve ferdi spor branşlarındaki antrenörlerin is tatmin düzeylerinin incelenmesi üzerine bir araştırma. Yayınlanmamış 
Yüksek Lisans Tezi,Gazi Üniversitesi, Sağlık Bilimleri Enstitüsü, Ankara.

Koçak, V.C. ve Güven, Ö.(2018). Voleybol antrenörü mesleki öz yeterlik ölçeği geçerlik ve günenirlik çalışması.SPORMETRE,16(2),162-177

Koçak, V.C. (2019) Antrenör adaylarının antrenör öz yeterlik düzeylerinin incelenmesi. SPORMETRE, 17(1),55-62

Kowalski, C.L. (2007). An analysis of coaching efficacy in volunteer soccer coaches. Master Thesis, North Iowa University. U.S.A.

Köksal F. (2008) . Antrenörlerin liderlik tarzları ile öz-yeterlilikleri arasındaki ilişki. Yayınlanmamış Yüksek Lisans Tezi, Selçuk Üniversitesi, Sağlık Bilimleri Enstitüsü, Konya.

Myers, N. D., Feltz, D. L., Chase, M. A., Reckase, M. D., ve Hancock, G. R. (2008). The coaching efficacy scale II-high school teams. Educational and Psychological Measurement, 68(6), 1059-1076.

Öcel, H. (2002). Takım sporu yapan oyuncularda kolektif yeterlik öz-yeterlik ve sargınlık ile başarı algı ve beklentileri arasındaki ilişkiler. Yayınlanmamış Yüksek Lisans Tezi, Hacettepe Üniversitesi, Ankara.

Pajares, F. ve Schunk, D.L. (2002). Self and self-belief in psychology and education: an historical perspective. Improving Academic Achievement. New York: Academic Press.

Schunk DH, (2009). Learning theories an educational perspective. (M. Şahin, Çev. Ed.). Ankara: Nobel Yayınevi.

Toklu, O. (2010). Tenis antrenörlerinde liderlik özellikleri ve öz yeterlilikleri arasındaki ilişkinin belirlenmesi. Yayınlanmamış Yüksek Lisans Tezi, Selçuk Üniversitesi, Sağlık Bilimleri Enstitüsü, Konya.

Unutmaz, V. ve Gençer T. (2017). Antrenör yeterlilik ölçeği II'nin Türkçe uyarlama çalışması. Journal of Sport Sciences Researches, 2(2), 69-78.

\section{Kaynakça Bilgisi / Citation Information}

Ermiş, E., Satıc1, A., Bostancı, Ö., İmamoğlu, O. ve Taşmektepligil, M.Y. (2018) Spor lisesi ve spor bilimleri fakültesi öğrencilerinin öfke ve saldırganlık düzeylerinin araştırılması. OPUS-Uluslararası Toplum Araştırmaları Dergisi , 14(20), 1211-1227. DOI: 10.26466/ opus. 605062 